\title{
The Effect of CPA and Urea Distribution on Growth of Banana Seedling Stage and Fate of Nitrogen
}

\author{
Lina Huang ${ }^{1, a}$, Wei $\mathrm{Xu}^{2, \mathrm{~b}}$, Shimin Cheng ${ }^{1, \mathrm{c}}$ \\ Zhiru Zhao ${ }^{1, \mathrm{~d}}$ and Shouxing Wei ${ }^{1,} \mathrm{e}^{*}$ \\ ${ }^{1}$ Tropical Crops Genetic Resources Institute, Chinese Academy of Tropical Agricultural \\ Sciences(CARTA), Danzhou,571737,China \\ ${ }^{2}$ Institute of Tropical Agriculture and Forestry, Hainan University, Haikou ,570228, China \\ ahuanglinahappy@sina.com, b515268002@qq.com, '867944012@qq.com, \\ d149477303@qq.com, eshouxingwei@163.com \\ * The Corresponding author
}

Keywords: Crosslinked polyacrylamide; Urea; Distribution method; Growth; Fate of Nitrogen

Abstract. Using pot experiment, study the L size crosslinked polyacrylamide (L - CPA) and urea with way of banana seedling growth and nitrogen absorption, leaching, residue, apparent loss of $\mathrm{n}$ to the influence of reasonable L - CPA in banana seedling stage. The results showed that in the banana seedling stage l-cpa and urea mixture or adsorption and distribution can significantly improve the high and nitrogen uptake of banana seedling stage, respectively, $16.62 \%$ and $19.26 \%, 29.44 \%$ and $49.15 \%$ respectively. The percentage of nitrogen in plant absorption was increased by 7.58 and 12.65 percentage points respectively, while the apparent loss decreased by 5.72 and 6.16 percentage points respectively. Compared with the application of urea nitrogen, the adsorption of l-cpa and urea could also significantly promote the accumulation of dry matter in banana seedling stage and increase $39.63 \%$. Reduced nitrogen leaching loss by 4.01 percentage points; In addition, the nitrogen absorption and nitrogen content of banana seedling stage were significantly higher than that of urea three times in plant absorption, and $7.41 \%$ and 2.65 percentage points respectively. To sum up, in banana seedling with L size crosslinked polyacrylamide with urea, appropriate USES adsorption with, will be more helpful in banana growth, promote the nitrogen absorption use, reducing the loss of nitrogen leaching and apparent, reduce the number of fertilization.

During the whole growth period of the banana, the growth of banana in the seedling stage directly affects the regularity of the growth of the banana, thus affecting the economic benefit of the banana ${ }^{[1-2]}$. The banana field seedling production, sale the heavy nitrogen, the traditional acupuncture point or cucumber in application of urea for many times, and after application of urea for flood irrigation or spraying on the moisture of excessive, cause seedling artificial cost is higher, low utilization rate of nitrogen fertilizer, serious water pollution, reduce soil quality and other issues. Excessive application of urea causes the concentration of nitrogen nutrients in the surrounding nitrogen of banana seedling stage, which can cause fertilizer damage, causing the plant to grow slowly and even die ${ }^{[3-4]}$. Therefore, it is of great significance to carry out the management of the water fertilizer of banana seedling stage science and to the high quality and high yield of bananas.

Water retention agent can effectively regulate soil water, heat and gas status, promote crop growth, reduce leaching loss of nutrients, improve fertilizer utilization rate, and have good protection of fertilizer and anti-leaching effect ${ }^{[5-8]}$. The application of SAP in banana seedling stage and the treatment of urea with urea can provide effective measures to solve the management of banana seedling stage. Crosslinked polyacrylamide (CPA) is used as a good stability, salt tolerance, good water retention and good SAP, better suited to the soil of clay in the south of the soil ${ }^{[9-10]}$. Based on this, this research adopts the S, M, L size of CPA with urea mixed fertilizer, the results show that compared with urea nitrogen fertilization once, CPA applied urea can significantly reduce the amount of nitrogen leaching, by an average $15.92 \%$; Increased nitrogen residues increased by $13.42 \%$ on average, and ${ }^{[11]}$ was the best result in the CPA. In addition, studies have shown that 
there are two kinds of mixed and adsorption methods of CPA and urea distribution, and there are


study, using pot experiment in seedling stage of banana as the research object, further study on L CPA and urea with different ways of banana seedling growth and nitrogen absorption, leaching, residue, apparent nitrogen to influence, such as the loss in banana seedling stage the most suitable match way, reasonable L - CPA in banana seedling stage.

\section{Materials and Methods}

Test Materials. The experiment was conducted on 20 July $2014 \sim 20$ October 2014 in the tropical fruit tree improvement center of the tropical agricultural academy of China. The soil of the supply test was brick red soil with a weight of $1.34 \mathrm{~g} / \mathrm{cm} 3, \mathrm{pH}$ value of 5.16 , the conductivity $35.89 \mathrm{mu}$ $\mathrm{s} / \mathrm{cm}$, organic matter $8.74 \mathrm{~g} / \mathrm{kg}$, the total nitrogen $0.768 \mathrm{~g} / \mathrm{kg}$, the quick acting nitrogen (ammonium nitrogen and nitrate) $157.22 \mathrm{mg} / \mathrm{kg}$; Instant phosphorus $7.32 \mathrm{mg} / \mathrm{kg}$; Instant potassium $90.83 \mathrm{mg} / \mathrm{kg}$.

The plantain seedlings of Brazil ( $7 \sim 8$ leaves) were supplied. The basin is a brown and red plastic basin with a size of $32 \mathrm{~cm} \times 23.5 \mathrm{~cm}$ x $28 \mathrm{~cm}$ (top diameter x height).

The fertilizer was urea ( $\mathrm{N} \mathrm{46 \% ),} \mathrm{calcium} \mathrm{magnesium} \mathrm{phosphate} \mathrm{fertilizer} \mathrm{(P2O5} \mathrm{12.5 \% ),}$ potassium chloride $(60 \%)$. The test is provided by Beijing hanli miao new technology co., LTD., which is a granule, with a diameter of $1.6 \mathrm{~mm} \sim 4 \mathrm{~mm}$.

Test Design. This experiment USES the single factor experiment design to CPA and urea with factors, this paper USES the base applied urea, urea solution respectively design L - CPA absorption (CPA - Ua), L - CPA mixed with urea (CPA Ub), urea (U1), three times add urea fertilizer treatments (U2), nitrogen CPA control treatment (CK), a total of 5, each processing repeat 3 times. The use of CPA is applied in accordance with 0.2 percent of the weight of the dry soil, and the nitrogen fertilizer is based on $0.25 \mathrm{~g} / \mathrm{kg}$ of soil, and the ratio of NPK is according to $\mathrm{N}$ : P2O5: $\mathrm{K} 2 \mathrm{O}=$ 22:8:15, potassium phosphate.

Test Management. Each basin has a dry soil of $13 \mathrm{~kg}$ (over $5 \mathrm{~mm}$ sieve). According to the design of the test, the corresponding CPA, urea, calcium magnesium phosphate and potassium chloride are taken. Before the basin, the urea solution is absorbed into the water, and the urea solution is absorbed completely, and the CPA granules and soil are fully mixed with the soil. Other treatments mix the CPA with the soil and urea. The above mixed soil is mixed with the phosphate fertilizer. The urea unit deals with a factor of one-third of the urea in the basin, and the other two thirds are applied in the ditch every other month. Select a uniform banana and plant it in the basin. 1 week after the transplanting of banana seedlings can be added to the shade net in the greenhouse to facilitate the delayed seedling, regularly weighing and watering, keeping the soil moisture content in the field for $60 \% \sim 80 \%$. The whole experiment lasted three months. Soil nitrogen leaching method adopts the intermittent leaching method, from the banana seedlings sprout after transplanting, every $15 \mathrm{~d}$ after leaching time, carried out in accordance with the $150 \%$ of field capacity water leaching, the next collection of leaching solution, the determination of the total nitrogen content of leaching solution.

Determination of Projects and Methods. The growth indicators of banana, dry matter and nitrogen, nitrogen, and determination methods refer to the references ${ }^{[11-15]}$.

Data Processing . Test data was used in Excel 2007 to carry out the multiple comparisons of Duncan's new complex extreme difference test (DMRT) using SPSS 13.0.

\section{Results and Analysis}

The Effect of CPA with Urea on Growth of Banana Seedling Stage. From table 1, it can be seen that compared with $\mathrm{CK}$, the application of nitrogen fertilizer can significantly increase the height of banana seedling stage and the area of inverted three leaf leaves, respectively, $83.08 \%$ and $375.84 \%$ respectively. Compared with U1, the application of CPA did not affect the number of leaves of banana seedling stage, stem coarse and three leaf leaf area, but it could significantly increase the plant height and was not affected by the method of CPA and urea treatment. The treatment of 
banana plant height by CPA - Ua and CPA - Ub was $16.62 \%$ and $19.26 \%$, respectively, higher than U2. Further analysis shows that there is no significant difference between the growth indicators of banana seedling stage between CPA - Ua and CPA - Ub treatment. Therefore, it can be seen that in the banana seedling stage, CPA and the effect of the treatment of urea kirsch are significantly higher than that of urea three times.

Table 1 the growth indicators of banana seedling stage were treated by different test

\begin{tabular}{ccccc}
\hline & \multicolumn{3}{c}{ growth index } \\
\cline { 2 - 5 } Treatment & $\begin{array}{c}\text { The } \\
\text { number } \\
\text { of leaves }\end{array}$ & Stem length $(\mathrm{cm})$ & $\begin{array}{c}\text { Spear thickness } \\
(\mathrm{mm})\end{array}$ & Three leaf area $\left(\mathrm{cm}^{2}\right)$ \\
\hline CK & $17.3 \pm 0.7 \mathrm{~b}$ & $22.9 \pm 0.2 \mathrm{~d}$ & $15.53 \pm 0.74 \mathrm{~b}$ & $0.0209 \pm 0.0063 \mathrm{c}$ \\
$\mathrm{U} 1$ & $19.0 \pm 0.6 \mathrm{a}$ & $37.9 \pm 1.0 \mathrm{c}$ & $16.73 \pm 0.35 \mathrm{ab}$ & $0.0991 \pm 0.0091 \mathrm{ab}$ \\
$\mathrm{U} 2$ & $17.7 \pm 0.3 \mathrm{ab}$ & $40.4 \pm 0.6 \mathrm{~b}$ & $18.83 \pm 0.82 \mathrm{a}$ & $0.0858 \pm 0.0088 \mathrm{~b}$ \\
CPA- Ua & $18.3 \pm 0.3 \mathrm{ab}$ & $44.2 \pm 0.9 \mathrm{a}$ & $18.43 \pm 0.39 \mathrm{a}$ & $0.0965 \pm 0.0047 \mathrm{ab}$ \\
CPA- Ub & $18.3 \pm 0.3 \mathrm{ab}$ & $45.2 \pm 0.7 \mathrm{a}$ & $17.77 \pm 1.32 \mathrm{ab}$ & $0.1164 \pm 0.0078 \mathrm{a}$ \\
\hline
\end{tabular}

Note: different lowercase letters within the same column mean difference between shi said test processing reached significant level (P 0.05 or less, $n=3$ ). Multiple comparison with Duncan the new poor law.

CPA with Urea on Banana Seedling Dry Matter Accumulation and Nitrogen Uptake. Table 2 shows that compared with $\mathrm{CK}$, the nitrogen fertilizer could significantly promote the banana seedling dry matter accumulation and nitrogen absorption, with an average of 1.62 times, 6.71 times.Relative to the U1, U2 and CPA Ub treatment were significantly improve banana seedling dry matter accumulation and nitrogen uptake, increased by $45.81 \%$ and $39.63 \%, 45.81 \%$ and $45.81 \%$ respectively.Compared with U2 processing, CPA - between the Ua and CPA Ub processing banana seedling stage were no significant difference of amount of dry matter accumulation, and CPA - Ua treatment significantly reduce nitrogen uptake, CPA Ub treatment were significantly improved, and the CPA Ub treatment increased by $7.41 \%$.To sum up, in banana seedling L size urea adsorption with CPA particles and can significantly improve the banana seedling dry matter accumulation and nitrogen uptake, and the effect is better than that of urea applied three times.

Table 2. The quality of dry matter and nitrogen uptake (g/strain) of banana seedling stage were treated by different test.

\begin{tabular}{llll}
\hline \multicolumn{2}{l}{ treatment } & Dry & resorption \\
\hline $\mathrm{CK}$ & & $38.82 \pm 1.62$ & $0.161 \pm 0.001$ \\
& $\mathrm{U} 1$ & $57.75 \pm 1.28$ & $0.837 \pm 0.009$ \\
& $\mathrm{U} 2$ & $66.17 \pm 2.01$ & $1.162 \pm 0.019$ \\
& $\mathrm{CPA}-\mathrm{Ua}$ & $62.28 \pm 0.50$ & $1.083 \pm 0.016$ \\
\multicolumn{2}{r}{ CPA- Ub } & $65.81 \pm 3.12$ & $1.248 \pm 0.029$ \\
\hline
\end{tabular}

The Influence of CPA with Urea on Nitrogen in Banana Seedling Stage .Table 3 analysis results of nitrogen in banana seedling stage. In terms of the absorption of nitrogen, the CPA - Ua and CPA - Ub improved 7.58 and 12.65 percentage points respectively compared with U1 respectively, and the CPA - Ub improved by 12.65 and 2.65 percentage points respectively compared with U1 and U2. Therefore, in a banana seedling urea fertilization, with L - the CLP can significantly promote the banana seedling nitrogen absorption, especially L - CPA particles with urea adsorption with three times better than urea fertilization, effectively reduce the number of urea fertilizer. During the banana seedling period, after 5 times of washing, there was a significant difference in the amount of nitrogen leaching between fertilizer treatments. Compared with U1 treatment, U2 treatment and CPA - Ub treatment could significantly reduce the loss of nitrogen leaching, respectively by 3.72 and 4.01 percentage points respectively, and there was no significant 
difference between the two. The analysis of nitrogen soil residues in the fertilizer nitrogen in seedlings was analyzed, and there was no significant difference between the other treatments except that U2 was significantly less than U1. Nitrogen is mainly used for plant absorption, leaching loss, nitrogen residues and surface (other losses). The table 3 shows that compared with the UI processing, CPA - Ua and CPA Ub apparent loss were significantly lower, lower 5.72 and $6.16 \%$ respectively, showed a urea process with L - CPA can effectively reduce the apparent loss. The above results show that in seedling stage a banana urea fertilization, with L - CPA with can significantly promote the nitrogen absorption, reducing the loss of nitrogen apparent, especially L $\mathrm{CPA}$ and the effect of urea adsorption with nitrogen absorption three times higher than urea fertilization, reducing leaching loss.

Table 3 nitrogen removal of banana seedling stage by nitrogen treatment (\%)

\begin{tabular}{ccccc}
\hline treatment & Plants absorbing & $\begin{array}{c}\text { leaching } \\
\text { loss }\end{array}$ & $\begin{array}{c}\text { soil } \\
\text { residual }\end{array}$ & $\begin{array}{c}\text { surface } \\
\text { loss }\end{array}$ \\
\hline $\mathrm{U} 1$ & $20.78 \pm 0.29 \mathrm{~d}$ & $16.59 \pm 0.28 \mathrm{a}$ & $31.06 \pm 0.35 \mathrm{a}$ & $31.57 \pm 0.77 \mathrm{a}$ \\
$\mathrm{U} 2$ & $30.78 \pm 0.60 \mathrm{~b}$ & $12.52 \pm 0.89 \mathrm{~b}$ & $26.55 \pm 0.89 \mathrm{~b}$ & $30.14 \pm 0.62 \mathrm{ab}$ \\
$\mathrm{CPA}-\mathrm{Ua}$ & $28.36 \pm 0.48 \mathrm{c}$ & $14.52 \pm 0.99 \mathrm{ab}$ & $31.27 \pm 0.45 \mathrm{a}$ & $25.85 \pm 0.85 \mathrm{~b}$ \\
$\mathrm{CPA}-\mathrm{Ub}$ & $33.43 \pm 0.89 \mathrm{a}$ & $12.88 \pm 0.81 \mathrm{~b}$ & $28.73 \pm 1.64 \mathrm{ab}$ & $24.96 \pm 2.78 \mathrm{~b}$ \\
\hline
\end{tabular}

\section{Discuss}

CPA is a water retention agent, not a water - making agent, must have certain conditions to give full play to its safe water function ${ }^{[13]}$. In China, there is a large amount of rain in southern China. The time of the drought is obvious. However, the rainfall interval is not long, and the frequency of medium and small rain is high, which can fully exert the absorption and releasing function of CPA ${ }^{[3-4]}$. At the same time, the root of the banana is succulent root, the soil moisture is too much or too little can affect the air permeability, the root growth and nutrient absorption unfavorable. In addition, the CPA is a polymer resin, which has a three-dimensional network structure and has certain crosslinking degree. The adsorption and exchange of urea nutrients through the CPA's own macromolecule structure and hydrophilic functional groups on the adsorption and exchange of ions in aqueous solution or soil are adsorbed and fixed by the CPA. The slow release of nitrogen when the plants need to be taken up by the plant, thereby promoting the growth of crops, and improving the efficiency of nutrient utilization ${ }^{[9-10]}$. The results of this study showed that during the banana seedling period l-cpa, the application of urea was significantly increased and the nitrogen uptake was increased, and the percentage of nitrogen in plant absorption was increased and the apparent loss decreased. This is similar to guo jianfang et al., liu xiaogang et al. ${ }^{[17-18]}$. The adsorption of 1-cpa and urea can not only increase the nitrogen absorption and nitrogen absorption and distribution of banana seedling, but also promote the accumulation of dry matter in banana seedling stage and reduce the loss of nitrogen leaching. This is consistent with the research results of gou chunlin et al.,

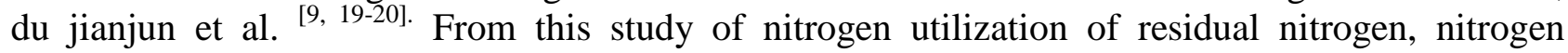
leaching, and apparent loss of crude nitrogen balance analysis, as for ammonia volatilization and L CPA soil adsorption of nitrogen nutrient remains to be further research. Another L - urea adsorption with CP and in seedling stage a banana using urea nitrogen fertilization can significantly improve nitrogen absorption use, reducing the loss of nitrogen leaching leaching and apparent, to reduce the pollution of nitrogen fertilizer and reduce pressure on agricultural environment has important significance.

\section{Reference}

[1] The development status of banana industry in guangdong province in 2011 [J]. Guangdong agricultural science, 2012 (5) : 12-14, 26

[2] fan xiaolin. Banana nutrition and fertilizer [M]. Beijing: China agriculture press, 2007

[3] Lin, zheng liyan, liao zhiqi, et al. Research on soil fertility in hainan banana garden [J]. Soil and 
fertilizer in China, 2007 (2) : 26-30

[4] wei shouxing, Chen zhongyuan. Production technology of banana anniversary [M]. Beijing: China agriculture press, 2008

[5] The research and application progress of soil ameliorators [J]. Ecological environment, 2008, 17 (3) : 1282-1289

[6] The application of chemical control technology in water-saving agriculture [J]. Water saving irrigation, 2001 (3) : 4-6

[7] Busscher W J, Bjorneberg D L, Sojka R e. Field application of PAM as an amendment in deep tilled US southeastern coastal plain soils. Soil \& Tillage Research, 2009, 104:215-220.

[8] Stevens C J, Dise N B, Gowing D j. of Regional trends in soil acidification and exchangeable metal concentrations in base to the acid deposition rates $[\mathrm{J}]$. Journal of Environmental Pollution, 2009, 157:313-319

[9] The influence of water retention agent and nitrogen fertilizer on water conservation and fertilizer efficiency [J]. China agricultural science, 2011, 44 (19) : 4015-4021

[10]Zhang Wo. [10] aquasorb research on the influence of soil physical and chemical properties [D]. Beijing: China academy of agricultural sciences, 2009.

[11] huang lina, zhao zhiru, cheng shi-min, et al. The effects of the polyacrylamide on the growth of the seedling stage of the banana and the effect of nitrogen in the plant $[\mathrm{J}]$ jiangsu agricultural science, 2016, 44 (10) : 218-221

[12] he xusheng, he health, zou shaowen. Application of water retention agent as fertilizer nutrient sustained-release carrier [J]. China soil and fertilizer, 2008 (04) : 5-9

[13] huang zhanbin. Application principle and technology of agricultural water retention agent [M]. Beijing: China agricultural science and technology press, 2005

[14]liu yongxia, zhou zhaoxi, tang fanling, et al. Quantitative analysis of the relationship between leaf area and leaf morphology of Brazilian banana leaf [J]. Journal of tropical crops, 2013, 34 (9) : 1641-1645

[15]The analysis method of soil agricultural chemistry [M]. Beijing: China agricultural science and technology press, 2000.

[16]liu xuejun, zhao zijuan, ju xiaotang, et al. Effects of nitrogenous fertilizer on yield of winter wheat, utilization of nitrogen fertilizer and nitrogen balance [J]. Ecological journal, 2002, 22 (7) : 1122-1128

[17] guo jianfang, li chengxue, xie chunqiong, Yang qiao hua. Research on the release effect of water retention agent on urea. Chinese agriculture bulletin, 2013, 29:103-108.

[18]liu xiaogang, Yin xin, fu na, et al. Effects of water, nitrogen and water retention agent on nitrogen utilization of small coffee. [J] journal of mechanical engineering, 2014, 32:547-552

[19]du jianjun, yi chunlin, cui yingde et al. Effects of water retention agents on the loss of ammonia volatilization of nitrogen fertilizer and nitrogen phosphate fertilizer [J]. Journal of agricultural environmental science, 2007, 26 (4) : 1296-1301.

[20]member learning feng, wang, wu, et al. Research on leaching loss in soil nutrients by polyacrylamide [J]. Journal of agricultural environmental science, 2005, 24 (5) : 929-934. 